\title{
The effect of extensive mesencephalic central gray lesions on responses to reinforcing brain stimulation'
}

VERNE C. COX AND ELLIOT S. VALENSTEIN

FELS RESEARCH INSTITUTE, YELLOW SPRINGS, OHIO

Extensive central gray lesions did not interfere with septal self-stimulation behavior or escape responding to aversive dorsomedial tegmental stimulation.

Electrical stimulation of various neural sites may produce motivational consequences which result in appetitive (self-stimulation) or defensive (escape) behavior (Olds, 1962). The diversity of neural sites capable of producing motivated behavior has led to speculation about the way these sites are related. The possibility of some critical locus for these effects has prompted several investigators to examine the changes in responses to reinforcing brain stimulation following the production of brain lesions (Olds, 1964; Valenstein \& Campbell, 1966; Ward, 1960, 1961). A relatively unexplored area, the mesencephalic central gray, is of particular interest because of its many connections with brain stem, limbic, and diencephalic structures including positive and negative reinforcing areas.

Central gray connections with positive reinforcing areas (the lateral and posterior hypothalamus and septum) and negatively reinforcing areas (the periventricular hypothalamic structures) have been described by Bucher \& Burgi (1953), Cowan, Guillery, \& Powell (1964), Guillery (1957), Morest (1961) and Nauta (1956, 1958, 1960). Connections with the lateral hypothalamus and septum are primarily via the medial forebrain bundle, mammillary peduncle, and mammillotegmental tract. The septal area is also connected to the central gray by way of the hippocampus and fornix fibers. Connections with the periventricular and posterior hypothalamic structures are via the dorsal longitudinal fasiculus.

The mesencephalic central gray itself may play an important role in the mediation of pain. Anatomical evidence in support of this view has been provided by Mehler (1962), and Mehler, Feferman, \& Nauta (1960), who have described major fiber termination of the spinothalamic "pain tract" in the central gray. Behavioral studies have demonstrated the aversive properties of electrical stimulation of the central gray (Abrahams, Hilton, \& Zbrozyna, 1960; Livingston, 1962; Olds \& Olds, 1962; Olds \& Peretz, 1960; Skultety, 1963; Speigel, Kletzin, \& Szekely, 1954; Valenstein, 1965; Wilkinson $\&$ Peele, 1963). Lesions in this area have been reported to decrease responsiveness to noxious peripheral stimuli (Melzack, Stotler, \& Livingston, 1958; Skultety, 1958).

The present study reports the effects of extensive central gray lesions on septal self-stimulation and escape behavior from aversive dorsomedial tegmental stimulation posterior to the lesion site.

\section{Method}

Six male albino rats $(300-400 \mathrm{gm})$ of the Holtzman strain were used. Two Ss were implanted with septal electrodes (Diagonal Band of Broca) and four Ss were implanted with dorsomedial tegmentum electrodes. With the skull level between the lambda and bregma, the tegmental electrodes were inserted at an angle of 25.5 degrees from the vertical, $7.0 \mathrm{~mm}$ posterior to the bregma, $2.5 \mathrm{~mm}$ lateral and $4.75 \mathrm{~mm}$ below the skull surface. All six Ss received bilateral electrolytic lesions of the mesencephalic central gray. The current used for lesions was 2.0 ma DC delivered for 20-25 sec. Following lesions and electrode implantation, the response of Ss to brain stimulation was evaluated. Self-stimulation was observed in a conventional lever pressing chamber. Lever presses were reinforced with a $0.5 \mathrm{sec}$. train duration of pairs of biphasic rectangular pulses (pulse duration $0.2 \mathrm{msec}$.; pulse pair frequency $100 / \mathrm{sec}$.) delivered on a CRF schedule. After initial lever pressing training animals received five $24 \mathrm{~min}$. tests. A test consisted of three $8 \mathrm{~min}$. sessions each preceded by a 2 min. "warm-up" period. Current levels were $0.3,0.65$ and $1.0 \mathrm{ma}$ for the three consecutive sessions. Lever pressing rates were recorded automatically. Escape behavior from continuous tegmental stimulation (current range 75-350 $\mu$ A) with the same parameters as described for the septal stimulation was observed in a two-compartment shuttlebox ( 60 by $25 \mathrm{~cm}$ and $42.5 \mathrm{~cm}$ high). Photo electric cell assemblies located $12.5 \mathrm{~cm}$ from each end of the box were used with appropriate circuitry to record escape responses.

\section{Resulis and Discussion}

Lesions in Ss with septal electrodes destroyed 90$100 \%$ of the central gray matter under the superior colliculi from the level of the Edinger-Westphal nucleus to the anterior margin of the inferior colliculi. Additional posterior damage spared the dorsal and deep tegmental nuclei, but destroyed central gray matter above and anterior to these nuclei. Figure 1 illustrates the destruction in one of these animals. Both septal animals lever pressed at rates comparable to or higher than that typically observed in unlesioned animals with similar electrode placements. Average response rates for the five

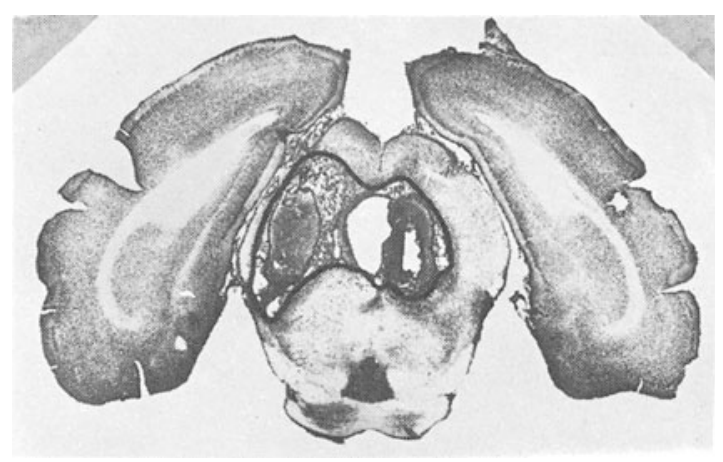

Fig. 1. Central gray damage in animal with reinforcing septal electrode. 
tests were 70 and 95 responses per minute for the two Ss.

Three Ss with aversive dorsomedial tegmental electrodes suffered $90-100 \%$ destruction of the cross sectional extent of the central gray including the dorsal longitudinal fasciculus. The remaining $\mathrm{S}$ suffered $80 \%$ damage. The major destruction in all animals extended from the level of the commissure of the superior colliculi to the brachium of the inferior colliculus. Figure 2 illustrates the extent of central gray destruction in one of the three animals suffering the more extensive destruction. All four Ss escaped vigorously from dorsal central gray stimulation posterior to the lesion site. The escape latencies, which averaged less than $1.5 \mathrm{sec}_{0}$, were not different from those typically observed at comparable intensities in unlesioned animals with similar electrode placements.

It appears that extensive mesencephalic central gray lesions do not interfere with either septal self-stimulation or escape behavior from dorsomedial tegmental stimulation. Similar observations on escape behavior of cats has been reported by Skuliety (1963). It is concluded that the aversive properties of dorsomedial tegmental stimulation and the positive properties of septal stimulation are not dependent upon the integrity of pathways such as the dorsal longitudinal fasciculus which traverse the rostral half of the central gray.

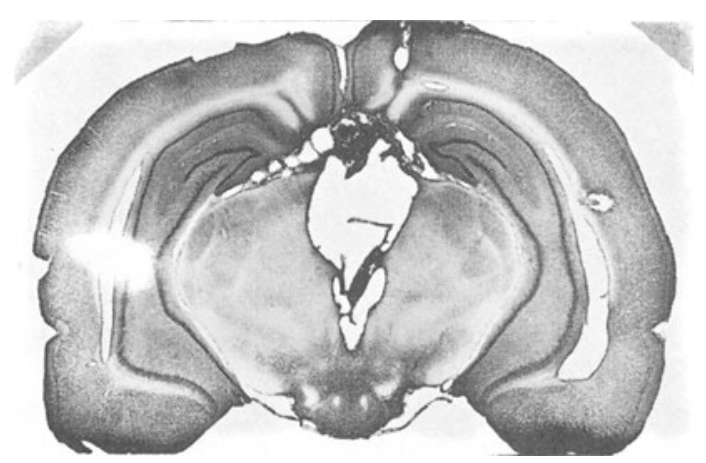

Fig. 2. Central gray damage in animal with aversive tegmental electrode.

\section{References}

Abrahams, V. C.. Hilton, S. M., \& Zbrozyna, A. Active muscle vasodilation produced by stimulation of the brainstem: its significance in the defence reaction. J. Physiol., 1960, 154, 491513

Bucher, V. M., \& Bürgi, S. M. Some observations on the fiber connections of the di- and mesencephalon in the cat. J. comp. Neurol., 1953, 99, 415-435.
Cowan, W. M., Guillery, R. W.. \& Powell. T. P. S. The origin of the mamillary peduricle and other hypothalamic connexions from the midbrain. J. Anat., 1964, 98, 345-363.

Guillery, R. W. Degeneration in the hypothalamic connexions of the albino rat. J. Anat., 1957, 91,91-115.

Livingston. W. K. Pain mechanisms and problems, In J, D. French \& R. W. Porter (Eds.), Basic research in parapleuia. Springfield, I1l.: Thomas, 1962.

Mehler, $\mathbf{W} . \mathbf{R}$. The anatomy of the so-called "pain tract" in man: an analysis of the course and distribution of the ascending fibers of the fasiculus anterolateralis. In J. D. French \& R. W. Porter (Eds.), Basic research in parapleoia. Springfield, Ill.: Thomas, 1962.

Mehler, W. R., Feferman, M. E., \& Nauta, W. J. H. Ascending axon degeneration following anterolateral cordotomy. An experimental study in the monkey. Brain, 1960, 83, 718-750.

Melzack. R., Stotler, W. A., \& Livingston, W. K. Effects of discrete brain-stem lesions in cats on perception of noxious stimulation. $J$. Neurophysicl., 1458, 21, 353-367.

Morest, K. D. Connexions of the dorsal tegmental nucleus in rat and rabbit. J. Anat., 1961, 95, 229-246.

Nauta, W. J. H. An experimental study of the fornix in the rat. $J$ comp. Neurol., 1956, 104, 247-272.

Nauta. W. J. H. Hoppocampal projections and related neural pathways to the mid-brain in the cat brain. Brain, $1958,81,319-340$.

Nauta, W.J.H. Some neural pathways related to the limbic system. In E. Ramey \& D. O'Doherty (Eds.), Electrical studics on the unanesthetized brain. New York: Hoeber, 1960.

Olds, J. Hypothalamic substrates of reward. Physiol. Rev., 1962 $42,554-604$.

Olds, J., \& Olds, M. E. The mechansisms of voluntary behavior. In R. G. Heath (Ed.), The role of pleasure in behavior. New York: Hoeber, 1964.

Olds. J., \& Peretz, B. A motivational analysis of the reticular activating system. EEG clin. Neurophysiol., 1960, 12, 445-454.

Olds, M. E.. \& Olds, J. Approach-escape interactions in the rat brain. Amer. J. Physiol., 1962, 203, 803-810.

Skultety, F. M. The behavioral effects of destructive lesions of the periaqueductal gray matter in adult cats. $J$. comp. Neurol., $1958,110,337-366$.

Skultety, F. M. Stimulation of the periaqueductal gray and hypothalamus. Arch. Neurol., 1963, 8, 608-620.

SpiegeI, E, A., Kletzkin, M., \& Szekely, E. G. Pain reaction upon stimulation of the tectum mesencephali. $J$. Neuropath. exp. Neurol., 1954, 13, 212-220.

Valenstein, $\mathbf{E}$. S. Independence of approach-escape reactions to electrical stimulation of the brain. J. comp. physiol. Psychol. $1965,60,20-30$

Valenstein, E. S., \& Campbell, J. F. Medial forebrain bundlelateral hypothalamic area and reinforcing brain stimulation. Amer. J. Physiol., 1966, in press.

Ward, H. P. Basal tegmental self-stimulation after septal abiation in rats. AMA arch. neurol. Psychiat., 1960, 3, 158-162.

Ward, H. P. Tegmental self-stimulation after amygdala ablation. AMA arch. neurol. Psychiat., 1961, 4, 657-659.

Wilkinson, H. A., \& Peele, T. L. Intracranial self-stimulation in cats. J. comp. Neurol., 1963, 121, 425-440.

\section{Note}

1. Supported by NIH research grant M-4529 and Career Development Award MH-4947, NASA research grant NsG-437, and NIH postdoctoral fellowship MH-25, 749 . 